\title{
The investigation of internal pressure development in convective drying of shrinking and non-shrinking materials using green and fired clay as an example
}

\author{
Adamska, A. ${ }^{a^{*}}$; Pakowski, Z. ${ }^{\text {a }}$; Adamski, R. ${ }^{\text {a }}$ \\ ${ }^{\text {a }}$ Faculty of Process and Environmental Engineering, Lodz University of Technology, Lodz, Poland \\ *E-mail of the corresponding author: anna.adamska@dokt.p.lodz.pl
}

\begin{abstract}
The aim of present research was to measure and analyze the dynamic changes of internal pressure in shrinking vs. non-shrinking materials during convective drying for the use as a possible process control method.

Drying experiments were carried out on wet and fired clay at $50^{\circ} \mathrm{C}$ and $60^{\circ} \mathrm{C}$. In addition, the shrinkage curve was investigated. Experimental measurements show the existence of 4 stages of the process. The comparison of the results for wet and fired clay shows differences in pressure trends.

During drying the internal pressure changes from underpressure to overpressure at the level of $3 \div 5 \mathrm{kPa}$, what correlates well with transition from the first to the second drying period.
\end{abstract}

Keywords: ambient pressure drying; clay; shrinkage; pressure evolution 


\section{Introduction}

Ceramics is one of the oldest man-made materials and finds wide applications eg. in building sector (bricks, tiles), electric power industry (insulators), home and garden utensils (pottery) and advanced industries (ceramic filters, refractory materials etc.) [1].

Traditionally the cost of a product of the ceramic industry includes 30-40\% of energy costs. The mass of which green ceramics is formed is based on clay, a natural aluminosilicate mineral, with necessary additives and water.

The removal of water from green ceramics consists of several stages, each of them requires properly selected drying process parameters in order to avoid deformation and cracking of the preformed elements [2]. Although the shrinkage of green ceramics in drying is small it is enough to cause these adverse effects if the evaporation rate is too high or uneven.

The losses caused by cracking in the production of ceramic tiles in the EU countries alone are estimated as 200 million euro per annum. Losses due to cracking and deformation are also inevitable in the production of decorative ceramics - stove tiles, ornaments or sculptures [3].

Literature survey and industrial experience indicate that this negative outcome of drying can be eliminated by slow or better intermittent drying. In intermittent drying the ceramics is dried in two repeating cycles: in hot air and in ambient air. During hot air drying the processs is fast, which causes shrinkage and resulting build-up of internal stresses, while in ambient air the process is slow and the stresses relax. The cycles are repeated and may be of equal or of variable duration. The time of each cycle is set on the basis of on-line measurement of drying kinetics and/or the exiting air temperature and humidity. The time of the cycle is calculated on the basis of an earlier developed drying model [4].

Drying related stresses in shrinking solids are important in drying many industrial products. Gradient of moisure content and related stresses lead to deformation and cracking [5].

From theoretical analysis it follows that internal pressure in the wet solid varies during the process of drying. So far the values of capillary and liquid pressure in the wet solid were predicted [6,7]. The direct measurement of this pressure was difficult. One of the first works published in 1996 used a complex experimental procedure to measure drying induced stresses in colloidal capillary-porous solids such as peat. To measure the internal pressure 4 to $5 \mathrm{~mm}$ rubber hollow spheres filled with water were placed in the sample during casting. They were connected by thin lines to external manometers. Stresses were measured with microtensometers. The distributions of capillary and internal pressure as a function of moisture content were presented [8]. Experimentally the internal capillary pressure was measured by Holt [9] in autogeneous shrinkage of concrete. Using a thin tube immersed in the middle of the block height and an external pressure transducer it was found 
that the internal pressure is initially negative in the CRP and then turns positive in the FRP and at the end of the proces this pressure relaxes to the ambient value. In general, due to wide variety of wet solids an universal method of internal pressure measurement and interpretation is still being sought. Such measurement may provide valuable information on development of stresses in the material during drying [10].

The aim of this work is the analysis of transport of moisture in drying using the evolution of experimentally measured internal pressure in both wet green and fired clay. By using minature pressure transducers and telemetry such pressure can be messured in situ an the results transmitted to the required place. The obtained results may be used for control of the drying air parameters in response to the developing stresses in industrial scale, possibly also for many other shrinking materials.

\section{Materials and Methods}

\subsection{Material specification}

In the experiments performed in this work a clay material produced by Bolesławiec Refractory Materials Works, Bolesławiec, Poland was used. It is commonly used for manufacturing of artwork pieces, sculptured tiles etc. As plastifier 0.25 to $0.3 \%$ w.b. of water glass is added to mineral clay by the manufacturer.

The skeletal density of dry (non fired) clay measured by helium pycnometer is 2626.96 $\mathrm{kg} / \mathrm{m}^{3}$ and its porosity 0.3 . The purchased press formed clay block of moisture content 0.3 $\mathrm{kg} / \mathrm{kg}$ was directly used (in order to eliminate introduction of additional stresses) to cut cylindrical samples of $32.2 \mathrm{~mm}$ diameter and $27 \mathrm{~mm}$ tall.

\subsection{Drying experiments}

The convective drying experiments were preformed in a drying tunel described in detail elsewhere [11].

Two samples were used simultaneously in the experiment. One of them was placed on a rotating tray suspended under an electronic balance. This sample was armed with two thermocouples, one with its bead close to the periferal surface of the sample and the other placed axially. Both were connected to a transducer/transmitter situated on the tray and their signal transmitted to the computer. Both bases of the clay cylinder were covered tightly by perspex disks to eliminate heat and mass transfer to these surfaces.

The tray slowly rotated in order to equalize heat and mass transfer of the peripheral surface. The actual mass of the sample was continuously monitored by an electronic balance. The other sample was stationary and had a syringe needle with miniature pressure transducer inserted axially to measure axial pressure variations in time. Accurcy of measurements was: weight $10 \mathrm{mg}$, temperature $\pm 1^{\circ} \mathrm{C}$, pressure $\pm 16 \mathrm{~Pa}$. 
Drying experiments were performed in temperatures of $50^{\circ} \mathrm{C}$ and $60^{\circ} \mathrm{C}$ with air velocity 1 $\mathrm{m} / \mathrm{s}$. Each experiment continued for ca. $10 \mathrm{hrs}$ until equilibrium. The dried samples were then dried in an oven at $105^{\circ} \mathrm{C}$ to measure the remaining moisture. The difference of measured internal absolute pressure and actual atmospheric pressure was used for the analysis in Section 3.

\section{Results and discussion}

\subsection{Shrinkage curve}

The value of moisture content where shrinkage stops is on the level of critical moisture content ca. $0.19 \mathrm{~kg} / \mathrm{kg}$. All data points show a characteristic linear shrinkage behavior which is reported in literature for many other clays[13,14].

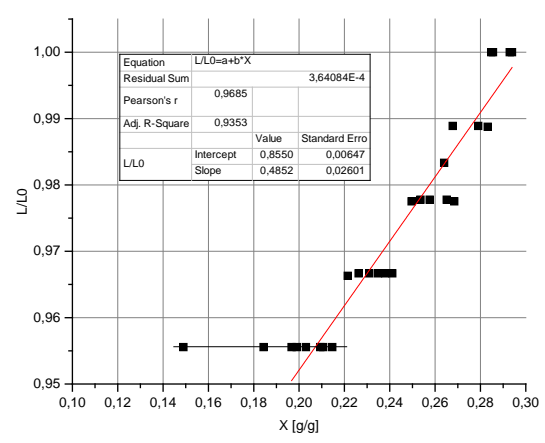

Fig. 1. Shrinkage curve

The dependence of sample dimension on its moisture content can be approximated with a straight line of the following form:

$$
\frac{L}{L_{0}}=0.855+0.4852 X
$$

By theory the linear shrinkage coefficient $\varepsilon_{\mathrm{L}}=0.4852$ which will be used in drying process simulation, is one third of the volumetric shrinkage coefficient $\varepsilon_{\mathrm{V}}$. During drying the linear shrinkage is only ca. $5 \%$, yet it is enough to create stresses above the strength of the solid.

\subsection{Results of drying experiments}

Fig. 4 presents the experimenal results (only data points -no curves fitted) for green clay at $50^{\circ} \mathrm{C}$ and $60^{\circ} \mathrm{C}$. Fig. 4a and 4c contain the internal pressure (gray), moisture content (blue) and solid temperature in the axis of the sample (red) evolution. Fig. 4c and 4d show the external conditions in the tunnel. The air temperature was the only controlled parameter. 
(a)

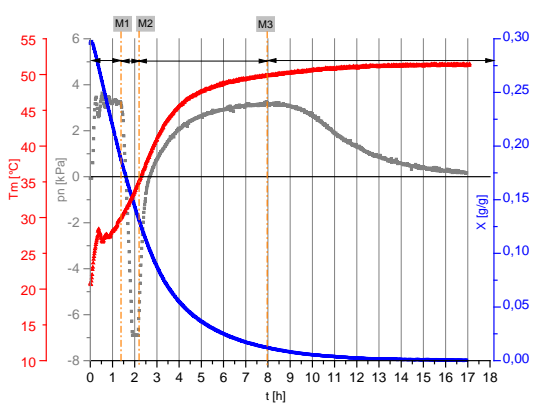

(b)

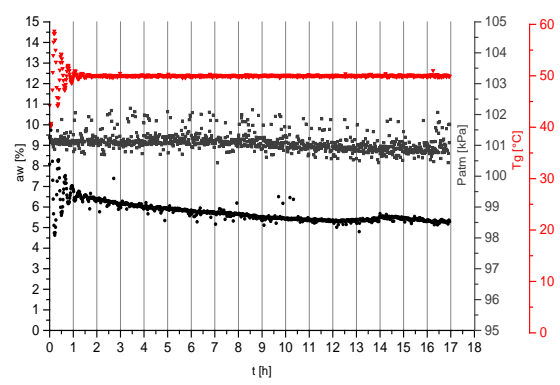

(c)

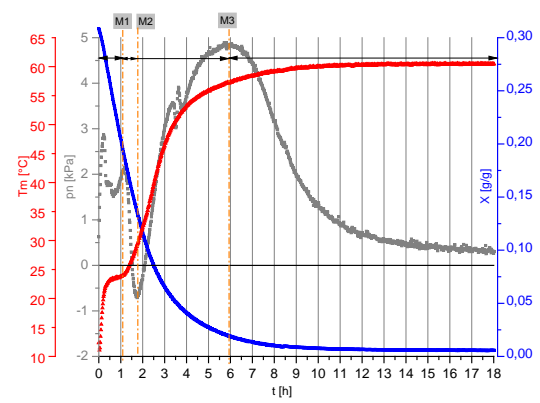

(d)

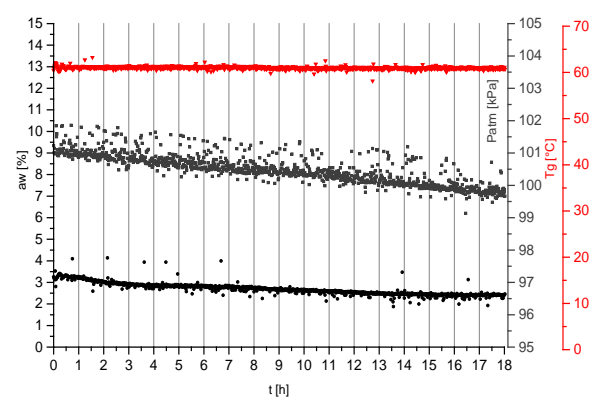

Fig. 4. The results for green clay drying at: (4a) $50^{\circ} \mathrm{C}(4 \mathrm{c}) 60^{\circ} \mathrm{C}$ where internal pressure (gray), moisture content (blue) temperature in the axis of the sample (red) and drying agent parameters for (4b) $50^{\circ} \mathrm{C}(4 \mathrm{~d}) 60^{\circ} \mathrm{C}$ where atmospheric pressure (gray), water activity (black) gas temperature (red)

Four distinct stages can be identified in the process. First for $1.5 \mathrm{hr}$ (from 0 to $\mathrm{M} 1$ ) an overpressure up to $2 \mathrm{kPa}$ at $50^{\circ} \mathrm{C}$ and $3 \mathrm{kPa}$ at $60^{\circ} \mathrm{C}$ develops during the heating-up period when the sample reaches the wet-bulb temperature and during a short CRP. It is a result of sample heating and thermal expansion of water. Second stage begins at transition from CRP to FRP ( $\mathrm{X}_{\text {crit }}=0.19 \mathrm{~kg} / \mathrm{kg}$ ) when a rapid fall of internal pressure is observed leading finally to underpressure (M1 to M2). Third stage (M2 to M3) starts after the shrinkage ceases i.e. after ca. 2 hrs and pressure begins to rise again simultaneously with solid temperatrure, which approaches the external temperature. The maximum of pressure is observed after 6-7 hrs and reaches $3 \mathrm{kPa}$ at $50^{\circ} \mathrm{C}$ and $5 \mathrm{kPa}$ at $60^{\circ} \mathrm{C}$. In the final stage pressure is relaxed to atmospheric pressure. For the fired clay wetted with distilled water, which shows no drying shrinkage, the results are shown in Fig.5. In this case three characteristic stages are observed. Here during heating stage ( 0 to W1) the internal pressure rises rapidly (there is no initial sustained overpressure as for green clay) and then falls to underpressure of $-2 \mathrm{kPa}$ at $50^{\circ} \mathrm{C}$ and $-0.8 \mathrm{kPa}$ at $60^{\circ} \mathrm{C}$ which is less than for green clay. CRP begins after ca. $0.5 \mathrm{hr}$ and lasts longer thn for green clay. At that stage the internal pressure begins to rise. When FRP 
is reached $\left(\mathrm{X}_{\text {crit }}=0.165 \mathrm{~kg} / \mathrm{kg}\right)$ ) rises to a maximum of $2.5 \mathrm{kPa}$ at $50^{\circ} \mathrm{C}$ and $3 \mathrm{kPa}$ at $60^{\circ} \mathrm{C}$, however, at $60^{\circ} \mathrm{C}$ the maximum is reached at the final segment of this stage when the solid temperature approaches air temperature (W1 to W2).

So far the evolution of internnal pressure was only predicted by some advanced models. No experimental work, including [9], so far has presented the evolution of internal pressure in such detail as the present work.

(a)

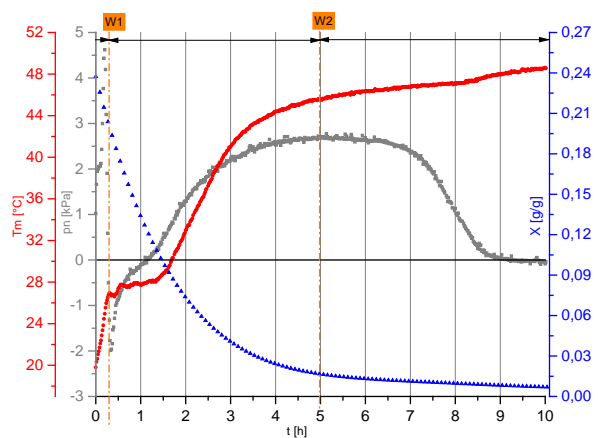

(b)

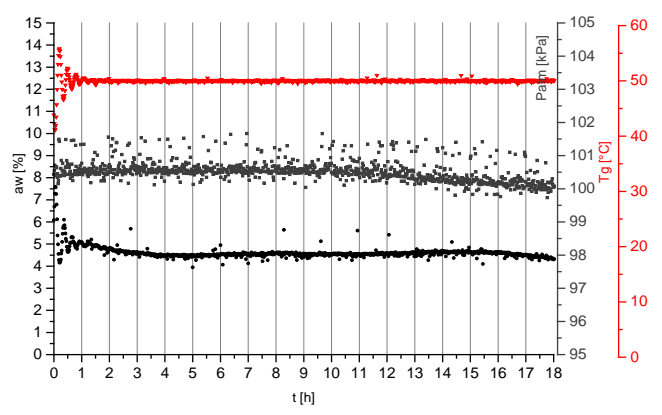

(c)

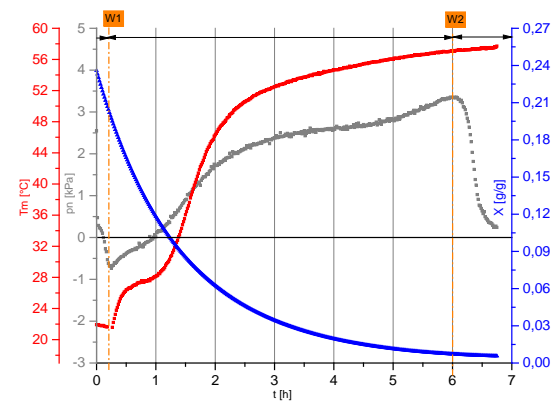

(d)

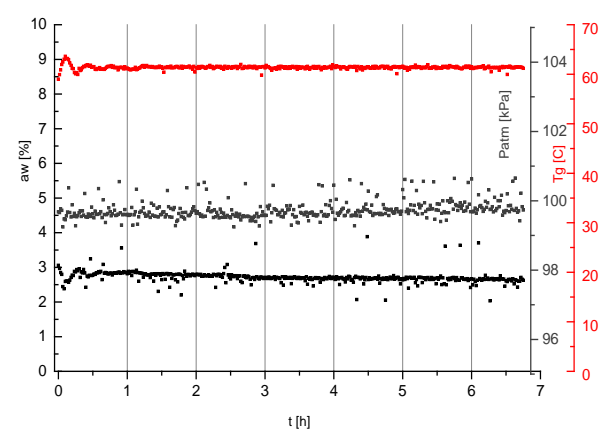

Fig. 5. The results for fired clay drying at : $(4 a) 50^{\circ} \mathrm{C}(4 \mathrm{c}) 60^{\circ} \mathrm{C}$ where internal pressure (gray), moisture content (blue) temperature in the axis of the sample (red) and drying agent parameters for (4b) $50^{\circ} \mathrm{C} \mathrm{(4d)} 60^{\circ} \mathrm{C}$ where atmospheric pressure (gray), water activity (black) gas temperature (red)

\section{Conclusions}

Based on the presented results, it can be concluded that the internal pressure is more sensitive to changes occurring in the material than the temperature or mass changes are. The analysis of pressure changes inside the drying both in non-shrinking and shrinking material, enables more precise observation of phenomena of moisture transport and changes in the nature of stresses generated in the dried material (initially compression and then 
stretching of the material). The obtained results will enable us to build a mathematical model to describe the convective drying process taking into account the internal pressure rate of change. Due to that, it will be possible to monitor the drying stresses generated in the material on a regular basis and control the process parameters so as to obtain the desired product without defects. Due to miniaturization of pressure sensors and the use of telemetric measurements, the method can be easily applied in an industrial scale to control the drying process.

\section{Nomenclature}

$\begin{array}{lll}\mathrm{L} & \text { sample length } & \mathrm{m} \\ \mathrm{t} & \text { time } & \mathrm{h} \\ \mathrm{P} & \text { pressure } & \mathrm{kPa} \\ \mathrm{T} & \text { temperature } & { }^{\circ} \mathrm{C} \\ \mathrm{X} & \text { moisture content } & \mathrm{kgkg}_{\text {d.b. }}{ }^{-1}\end{array}$

Greek letters

$\varepsilon \quad$ shrinkage coefficient

Subscripts

$\begin{array}{ll}\mathrm{L} & \text { linear } \\ \mathrm{V} & \text { volumetric } \\ 0 & \text { initial value }\end{array}$

\section{References}

[1] Pereira da Silva W., Pereira da Silva e Silva C. M.D., Duarte da Silva L., de Oliveira Farias V.S.; Drying of clay slabs: Experimental determination and prediction by twodimensional diffusion models. Ceramics International 2013, 39 (7), 7911-1919.

[2] Hubert J.; Léonard A.; Plougonven E.; Collin, F.; Boom clay drying behavior: experimental and numerical study. EuroDrying'2017 - 6th European Drying Conference, Liège, Belgium, 19-21 June 2017.

[3] Amoros J.L.; Sanchez, E.; Cantavella, V.; Jarque, J.C. Evolution of the mechanical strength of industrially dried ceramic tiles during storage. Journal of the European Ceramic Society 2003, 23, 1839-1845.

[4] Rybicki, A.; Sterowanie procesami suszenia materiałów wrażliwych na uszkodzenia skurczowe. Wydawnictwo Politechniki Poznańskiej 2012, 116 s.

[5] Augier, F.; Coumans, W.J.; Hugget, A.; Kaasschieter, E.F. On the risk of cracking in clay drying. Chemical Engineering Journal 2002, 86, 133-138.

[6] Chemkhi, S.; Khalfaoui, K.; Zagrouba, F. Modelling of saturated porous media 
drying: Heat and mass transfer coupled with the material mechanical behavior. International Journal of Chemical Engineering and Applied Sciences 2013, 3 (1), 1-6.

[7] Cáceres, G.; , Bruneau, D.; Jomaa, W.; Two-Phase Shrinking Porous Media Drying: A Modeling Approach Including Liquid Pressure Gradients Effects. Drying Technology 2007, 25 (12), 1927 - 1934.

[8] Gamayunov, N.I.; Gamayunov, S.N. J. Change in the structure of colloidal capillaryporous bodies in the process of heat and mass transfer. Journal of Engineering Physics and Thermophysics 1996, 69, 721-725.

[9] Holt, E.E.; Early age autogenous shrinkage of concrete, Technical Research Centre of Finland, VTT Publications 2001.

[10] Hassanizadeh, S.M.; Handbook of Porous Media, Third Edition, Edited by Kambiz Vafai, CRC Press, Chapter 2, 2015, 47-62.

[11] Pakowski, Z.; Głębowski, M.; Adamski, R. Modeling of drying of highly shrinking materials using hydrogels as an example. Drying Technology 2006, 24, 1075-1081.

[12] Ketelaars, A.A.J.; Drying deformable media kinetics, shrinkage and stresses. Drying Technology 1994, 12 (4), 983-987.

[13] Chemkhi, S.; , Jomaa, W.; Zagrouba, F. Application of a Coupled Thermo-HydroMechanical Model to Simulate the Drying of Nonsaturated Porous Media. Drying Technology 2009, 27 (7), $842-850$.

[14] Hasatani, M.; ltaya, Y. Fundamental study on shrinkage of formed clay during dryingviscoelastic strain-stress and heat/moisture transfer. Drying Technology 1992, 10 (4), 1013-1036. 